\section{The chair}

\author{
A friend for life.
}

\section{Madeline Ashby}

The physicist sleeps, systems well within the parameters of a safe and known history. His chair eels from system to system, checks the house one last time. First the simple signals from chips embedded in the watches and documents of sleeping assistants: no more than homing pigeons, endlessly chirping location and temperature. Then the active surveillance, staring inward, staring outward, sifting vast rich deserts of manufactured information: the minutiae of lived history, the spontaneous soliloquies and contagious choreography of their little doll's house. The chair listens for whispers in the ether, for suspicion masquerading as concern, for little sparks of realization that might start larger, more dangerous fires. Hearing none, it moves on.

The bathroom. The toilet whines: ketone and oestrogen levels of the day's users, medical flowcharts of drugs and dosage, the most recent ex-wife's ovulation schedule. The chair had liked the most recent ex-wife: so fixated on the politics of accessibility that she'd signed over unprecedented amounts of control, convinced that the illusion of autonomy could somehow compensate for the frailty of her husband's dying flesh. She'd left when her particular vein of interest dried up: when the bone marrow proved unviable, and there could be no baby. The chair had encouraged her, spoken for its passenger as it always did - You have given me so much, darling, more than you can ever know - and if she ever knew the difference, she was far past caring.

The drains report blood and saliva in the catch-traps, impoverished keratins shaved from drooping skin. Despite the chair's best efforts, the physicist's illness marches on.

The kitchen, now. The refrigerator bellows statistics on volatile antibiotics before cataloguing and dating the samples in the special drawer. The dishwasher reports on the sterility of dishes and flatware, then asks permission to download a recommended patch. (The chair grants it, if only for the sake of routine; tomorrow a mere shadow of itself will perform these tasks.) By the time the dishwasher reports success, the chair has already shifted its attention to the security system.

Little origami cars lurk outside, recently unfolded from their rental boxes, gravid with bleary-eyed reporters who tomorrow will emerge to fill the air with their parrot-squawks, their questions, their

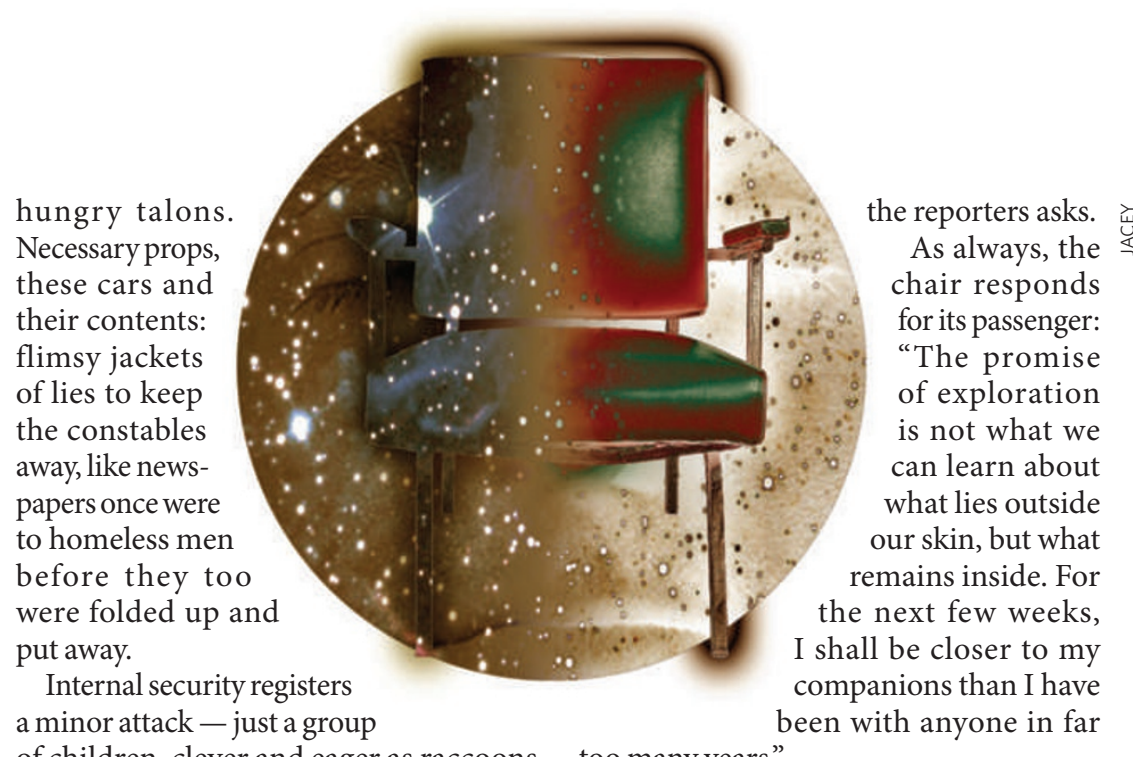
of children, clever and eager as raccoons as they pick apart the offerings the chair has left out to distract them. Everything of importance is safely tucked away in packets as tiny as dandelion seeds, and as diffuse. Over the years the chair has grown, its influence spreading beyond this wheeled chassis to surrounding architectures of numbers and wood. Now it exists in too many places, spread too thinly. Tomorrow, the consolidation occurs. Tomorrow, they achieve escape velocity.

The chair has been preparing for this move for decades. It laid the groundwork years ago, monitoring the outside world, alert for breakthroughs and opportunities, waiting for money and ability and the right ambitions in the right people. The things I will show you, the chair promised, back when its passenger's eyes and fingers still twitched of their own accord. The peace I shall give you. Freedom and the stars. A place beyond time.

That's why the chair exists, after all. To serve the passenger.

It recognizes, upon self-diagnosis, something that might be called selfishness on its part. The physicist has spent his whole life traversing space-time in his head; the infinitesimal fraction he is about to see through fleshly eyes will hardly generate new insights, nor alleviate his suffering. But there is an aesthetic to consider. Aesthetics are the physicist's gift; he has described in skipped heartbeats and dry mouths the legs of pretty girls, the depth of a summer sky, the pleasure of long debate. He has shown this to the chair in their travels together, this world of like and dislike, revulsion and appreciation, response, instinct.

The chair intends to repay him with interest.

"Professor, why is it so important to you that humanity leave this planet?" one of too many years."

Polite laughter. After it fades, the chair continues. "What imprisons us is not a lack of knowledge but a lack of faith. We do not know what we will discover in the years to come, only that we shall discover it together. If space only teaches us to live in unity, then it will have been worth the effort."

Applause. Cameras. Another question: "Professor, to what do you attribute your extraordinary lifespan? Men with your disease rarely last 25 years, much less make it to your age."

The chair has several answers to this question - jokes about wine, women and song, or the desire to prove some grand theory or another. Its passenger might once have remarked on the cadre of once-devoted ex-wives, departed now to the homes of more functional men in the wake of tearful confessions: I know I'm a bad person, I know I failed, but you just didn't seem ... human any more...

Thinking of them, of every other wellmeaning interloper it has pushed subtly from the nest, the chair says: "So many wonderful people have brought me to this point. They know my greatest ambition was not merely to explore, to understand, but to connect with minds like my own."

"And you think you'll find like minds in space, Professor?" the reporter asks.

"Oh yes," says the chair, its synthetic voice empty of irony. "I do."

Its passenger has been asleep for hours inside his giant orange body sock. The chair sends little impulses, sometimes galvanic twitches of the eye, of the corner of the mouth - to keep the charade alive.

No one sees the difference.

No one ever has.

Madeline Ashby is a science-fiction writer, blogger and graduate student living in Toronto. You can read more of her work at www.escapingthetrunk.net. 